\title{
Correspondence
}

\section{Simple method for stabilising umbilical catheters}

Sir,

We were interested in the letter from Gatrad (Archives, $1979,54,166)$. For the last 2 years we have used a method for stabilising umbilical catheters that has almost eliminated the problem of accidental dislodgement.

The umbilical cord is cut approximately $2 \mathrm{~cm}$ from the base, sterilised with povidone-iodine solution, and the lumen of the umbilical artery carefully dilated with fine forceps. A fluid-filled 5 FG catheter is then inserted and advanced in the usual manner. Once positioned, there should be free flow of arterial blood from the catheter. Position of catheter tip at the level of the 3rd or 4th lumbar vertebra is ascertained by $x$-ray. A 4-0 silk purse string suture is passed around the artery containing the catheter (not the entire base of the cord) and tied. One end of this suture is passed through the skin at the base of the cord. This is tied and cut so as to leave about 4-5 $\mathrm{cm}$ of free ends of the suture. These lengths of suture are then taped securely to the catheter just above its entry into the artery with standard $2.5 \mathrm{~cm}$ adhesive tape. A length of umbilical cord tape is passed around the waist of the infant and tied loosely. This loop is taped securely to the catheter 5-6 cm above the previous piece of tape, thus preventing the catheter from being dislodged should traction be applied to it during $x$-rays, routine care, or weighing of the infant. Povidone-iodine solution is applied twice daily to the cord and to the place at which the catheter is inserted until it is removed. The Figure shows this method of stabilisation in a low birthweight infant.

Techniques of catheterisation of umbilical vessels have been well described. Most methods of stabilisation combine purse string suturing around the catheter with taping of the catheter to the skin of the infant with or without a covering gauze dressing. This can lead to the catheter slipping through the purse string suture and to trauma to large areas of skin in low birthweight infants. Such areas subsequently serve as sites of increased fluid and protein loss and can be potential portals of entry for

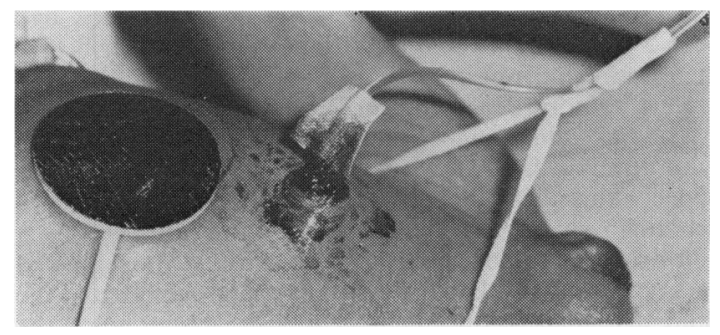

Figure Method of stabilising umbilical catheter. infection. Even paper tape may denude the skin of the small premature baby during the first 3 days of life.

Our technique, besides making accidental dislodgement of the catheter unlikely, additionally allows the umbilical cord to remain dry, and reduces the risk of colonisation with hospital-acquired organisms.

\section{JAmes M. AdAms AND ARnold J. Rudolph Department of Pediatrics, Baylor College of Medicine, Houston, Texas 77030, USA}

\section{Chloramphenicol and phenobarbitone -a drug interaction}

Sir,

I read with interest the Short Report by Bloxham et al. (Archives, 1979, 54, 76). The authors are mistaken in their belief that the interaction between these drugs has not been specifically reported in man. Windorfer and Pringsheim (1977) reported that premature and newborn babies $(n=20)$ who received phenobarbitone in addition to chloramphenicol and penicillin had lower levels of chloramphenicol than groups of comparable babies who received chloramphenicol alone $(n=29)$ or chloramphenicol and penicillin combined $(n=35)$.

The Short Report draws attention to the problem of drug interactions, and two points are worthy of mention. Chloramphenicol is known to inhibit the hepatic microsomal enzyme system (Adams et al., 1977) and it causes a reduction in phenobarbitone clearance (Koup et al., 1978) and raises the levels of phenytoin and other drugs (Christensen and Skovsted, 1969). It would therefore have been particularly interesting to have seen the trend in serial phenobarbitone concentrations in the two cases cited by Bloxham et al. Sodium valproate may offer no advantage, as although it appears to have little or no enzyme-inducing properties, it may in fact inhibit the microsomal enzyme system and this is presumably one mechanism by which an increase in phenobarbitone, phenytoin, and primidone concentration occurs when these drugs are used in combination with sodium valproate (Windorfer et al., 1975; Vajda et al., 1976).

It is imperative that all possible drug-drug interactions are considered when contemplating giving a combination of drugs. The importance of drug level monitoring, especially in these circumstances, is worth emphasising.

\section{References}

Adams, H. R., Isaacson, E. L., and Masters, B. S. S. (1977). Inhibition of hepatic microsomal enzymes by chloramphenicol. Journal of Pharmacology and Experimental Therapeutics, 203, 388-396. 
Christensen, L. K., and Skovsted, L. (1969). Inhibition of drug metabolism by chloramphenicol. Lancet, 2, 1397-1399.

Koup, J. R., Gibaldi, M., McNamara, P., Hilligoss, D. M. Colburn, W. A., and Bruck, E. (1978). Interaction of chloramphenicol with phenytoin and phenobarbital. Clinical Pharmacology and Therapeutics, 24, 571-575.

Vajda, F., Morris, P., Drummer, O., and Bladin, P. (1976). Studies on sodium valproate-a new anticonvulsant. In Proceedings of the Symposium on Clinical and Pharmacological Aspects of Sodium Valproate (Epilim) in the Treatment of Epilepsy, Nottingham, September 1975, pp. 92-100. Edited by N. J. Legg. MCS Consultants: Tunbridge Wells.

Windorfer, A., Sauer, W., and Gädeke, R. (1975). Elevation of diphenylhydantoin and primidone serum concentration by addition of dipropylacetate, a new anticonvulsant drug. Acta paediatrica Scandinavica, 64, 771-772.

Windorfer, A., and Pringsheim, W. (1977). Studies on the concentrations of chloramphenicol in the serum and cerebrospinal fluid of neonates, infants, and small children. European Journal of Paediatrics, 124, 129-138.

GEORGE W. RYLANCE Department of Child Health, University of Dundee, Ninewells Hospital, Dundee DD1 9SY

Drs Durbin and Winterborn comment:

We are pleased that Dr Rylance agrees with the aim of our report which was to stress the need for regular monitoring of blood levels when chloramphenicol is used in combination with other drugs, particularly enzymeinducing anticonvulsants. We did not measure serial phenobarbitone levels but neither patient showed evidence of toxicity in the form of unduly prolonged or increasing drowsiness. Any possible advantage of sodium valproate remains to be established by direct observation, but the evidence cited by Dr Rylance suggests that by inhibiting degradation, sodium valproate may actually increase the antibacterial activity of a given dose of chloramphenicol.

We thank Dr Rylance for drawing our attention to the report by Windorfer and Pringsheim (1977) which stated that addition of phenobarbitone to the combination (our italics) of chloramphenicol and penicillin reduced the serum chloramphenicol concentration in the neonate but not in infants or olderchildren. We do not agree that their report invalidates our claim to the first specific report of the interaction between chloramphenicol and phenobarbitone in man. Windorfer and Pringsheim used a photometric assay which fails to distinguish between active chloramphenicol and its breakdown products. Their finding of increased chloramphenicol levels in neonates and infants treated with penicillin and chloramphenicol can be attributed at least in part to penicillininduced renal retention of the breakdown products (Windorfer, 1972). It is therefore difficult to interpret their finding in neonates and infants that serum chloramphenicol concentration did not differ significantly between patients given chloramphenicol alone and those given the combination of chloramphenicol + penicillin + phenobarbitone. In the only group they were able to assess, they found no significant difference in the serum chloramphenicol levels of infants given chloramphenicol alone $(n=45)$ and of those given chloramphenicol + phenobarbitone $(n=40)$. The contradiction between their findings and ours may be explained by the relatively insensitive method of their study. They compared single measurements of serum (chloramphenicol + breakdown products) to the weight-related dose of chloramphenicol in children of different ages given different combinations of drugs, without allowing for the earlier duration of treatment. We suggest that Windorfer and Pringsheim would have demonstrated a significant effect of phenobarbitone on the serum level of biologically active chloramphenicol if, as we did, they had used a bioassay to measure the serum levels serially. In the event they did not.

\section{References}

Windorfer, A. (1972). Untersuchungen uber das Verhalten der Serumspiegel von Chloramphenicol bei gleichzeitiger Penicillingabe. Zeitschrift fur Kinderheilkunde, 112, 79-88.

Windorfer, A., and Pringsheim, W. (1977). Studies on the concentrations of chloramphenicol in the serum and cerebrospinal fluid of neonates, infants, and small children. European Journal of Paediatrics, 124, 129-138.

\section{G. M. Durbin Institute of Child Health, Francis Road, Birmingham B16 8ET \\ M. H. WINTERBORN Department of Paediatrics, East Birmingham Hospital, Bordesley Green East, Birmingham B9]5ST}

\section{Henoch-Schönlein syndrome after chickenpox}

Sir,

On the basis that one swallow does not make a summer, readers may not have paid too much attention to the letter from Halle (Archives, 1979, 54, 166) suggesting that it was the first account of Henoch-Schönlein syndrome after chickenpox. However, the association has been reported before. In a series of 88 children with HenochSchönlein nephritis (Meadow et al., 1972) we found that 5 children had had a specific infectious fever in the 6 weeks preceding onset of purpura. These illnesses were chickenpox in 2 children, and measles, rubella, and scarlatina in the other 3 . The onset of chickenpox had been 5 weeks in one child and 10 days in the other before the onset of purpura.

Furthermore Pedersen and Petersen (1975) reported a 2-year-old boy who developed Henoch-Schönlein syndrome 16 days after the onset of chickenpox. Their paper illustrates the difficulty in defining HenochSchönlein syndrome. Chickenpox can be followed by a nonthrombocytopenic purpura: it can also be followed by a nephritis. If the two were to happen together and the child also had a tummy ache or an aching joint the diagnostic label would be Henoch-Schönlein syndrome. 